\title{
Development of the Pregnancy-related Empowerment Scale
}

\author{
Carrie S. Klima*, Susan C. Vonderheid, Kathleen F. Norr, Chang G. Park \\ College of Nursing, University of Illinois Chicago, USA
}

Copyright $(\mathcal{C} 2015$ by authors, all rights reserved. Authors agree that this article remains permanently open access under the terms of the Creative Commons Attribution License 4.0 International License

\begin{abstract}
Patient-centered care that empowers individuals to take control of their health can improve health outcomes, especially during pregnancy. This study developed and tested a pregnancy-related empowerment scale (PRES). Phase 1 developed and validated a 16 -item scale using expert panel review, focus group and think-aloud interviews with pregnant women and a small pilot. Phase 2 used committee translation and cognitive interviews to establish a conceptually equivalent Spanish version. Phase 3 used survey data from 365 pregnant women to establish high scale reliability $(\alpha>0.90)$. Confirmatory factor analysis was consistent with four conceptual dimensions of empowerment: provider connectedness, skillful decision-making, peer connectedness and gaining voice. The PRES offers a reliable and valid measure for English and Spanish-language women in clinical practice and research related to prenatal care innovations.
\end{abstract}

Keywords Empowerment, Centeringpregnancy, Group Care, Prenatal Care, Measurement, Instrument Development

\section{Introduction}

The purpose of this study was to develop a valid and reliable measure of pregnancy-related empowerment (PRES), available in English and Spanish, for lower literacy populations. Empowerment is a complex multidimensional concept that has been described as "an ongoing process of enabling individuals and groups to improve capacities, to critically analyze situations and to take actions to improve those situations" [1].

Empowerment for childbearing women and families can be defined as increasing knowledge and capacities for health decision making, increasing awareness of rights for health and wellness, strengthening opportunities for social support, improved quality of health care and relationships with healthcare providers.[1] As pregnancy is a time when women are highly motivated to make changes to improve their health, prenatal care provides a unique opportunity to foster healthy behaviors both during and after pregnancy [2-5]. Measurement of empowerment during pregnancy can document increased capacity and link healthcare innovations with improved outcomes.

Although the US has the highest health care expenditures in the world, we rank 33rd in maternal and child health, near the bottom of most of the developed world [6]. Patient-centered innovations in prenatal care have been recommended as a mechanism to improve maternal and infant health [7]. A key element of patient-centered care is empowering patients to make informed decisions about their health and health care through health education, patient-centered communication and a power-sharing client-provider relationship [8, 9]. Many prenatal care innovations suggest that empowerment is a possible mechanism through which innovation affects health outcomes; that is, health-related empowerment mediates the relationship between the innovation and behavior change outcomes.

One such innovation is a group model of prenatal care, CenteringPregnancy, which has been introduced in a wide variety of settings across the US with positive impacts on maternal and infant health outcomes [10-13]. CenteringPregnancy provides greater health promotion education, group peer support, a collaborative patient-provider relationship; and self-management training and activities, all of which should contribute to empowerment $[12,13]$. Other more recent interventions include patient navigators, patient centered medical homes, and the use of mobile technology in prenatal care [14-17].

Evaluating the impact of prenatal care innovations on empowerment and subsequent health outcomes requires a valid and reliable measure of pregnancy-related empowerment. However, few such measures of health-related empowerment exist [18, 19]. Health-related empowerment scales should relate to the context and target population, but the majority of empowerment measures are related to chronic conditions [18, 20-21]. The only measure that focused on empowerment among pregnant and postpartum women was the Empowerment Questionnaire (EQ), which explored women's experiences with a 
community case management program, not prenatal care $[22$, 23].

Because there is no existing empowerment measure appropriate for prenatal care, a new measure specific to pregnancy-related empowerment is warranted. We developed the PRES for evaluating empowerment as an outcome of quality care and a mechanism of change in both standard and innovative prenatal care models.

\section{Design}

This methodological study was conducted in three phases to develop a valid and reliable measure of empowerment appropriate for low-literacy English and Spanish-language pregnant women. In Phase 1, we developed a pool of potential items, reduced items and established content validity and comprehensibility based on feedback from a professional expert panel and cognitive interviews with pregnant women. We then conducted a small field test for preliminary analysis of the scale's internal consistency. In Phase 2, the items were translated into Spanish and cognitive interviews with Spanish speaking pregnant women confirmed comprehensibility. In Phase 3, we examined the psychometric properties of the revised English and Spanish-versions using data from the baseline surveys of the first 365 participants in an ongoing study of ethnically diverse low-income women receiving prenatal care in several clinics throughout Illinois. All phases of this study were approved by the University of Illinois Ethical Review Board.

\section{Sample and Setting}

Phase 1. This phase included four different samples, three from women enrolled in CenteringPregnancy group and individual prenatal care and one Expert Panel. In addition to items from existing scales, relevant items were generated through secondary analysis of focus group data from the first CenteringPregnancy groups [12]. These participants were a subsample of 111 ethnically diverse low-income women in an East Coast hospital's prenatal clinic. Demographics specific to women participating in the focus group were not available, but in the total sample, $25 \%$ of the women were less than 20 years of age, $68 \%$ were having their first baby, and $70 \%$ began prenatal care in the first trimester. The second sample was an expert panel of seven nationally recognized professionals with expertise in prenatal care, empowerment and/or instrument development that reviewed items for content validity. The third sample included seven low-income African American women over 16 years of age who participated in group prenatal care at community health center in a large Midwestern city. These women attended a focus group and participated in cognitive interviews to determine comprehensibility and appropriateness of the items. The fourth sample included 135 low-income, African American and Latina women over 16 years of age who received group and individual care in three urban health centers in two large Midwestern cities. These women completed the empowerment scale to assess preliminary reliability of the scale.

Phase 2. In this phase the PRES was translated into Spanish by a committee of 3 bilingual women with Spanish as their first language. The Spanish PRES was then evaluated for appropriateness and comprehensibility using cognitive interviews with 11 women recruited from a University affiliated urban health center serving predominately low-income ethnic minority women. Women were included if they self-identified as Latina, spoke Spanish as their primary language, and had 12 years of education or less.

Phase 3. In this phase the study sample was a subsample from a larger study focused on evaluating preterm birth and other perinatal outcomes among low-income pregnant women attending prenatal care at 22 clinics in diverse locations across Illinois: the Chicago Metropolitan Area, Aurora, Rockford and Springfield. Women were enrolled in the parent study if they were less than 21 weeks pregnant, had a medically low-risk pregnancy, and planned to attend the same clinic throughout their pregnancy. Women less than 21 weeks were excluded as the group prenatal care sessions began at 18-20 weeks. For our subsample, the target sample size was 160 for each language or 10 cases per item. This sample size was determined based on the ability to conduct data reduction techniques (i.e., factor analysis) and obtain reliable solutions [24]. The final subsample of 365 included 166 women who completed the Spanish-language interview and 181 who completed the English-language interview. Women chose whether to be interviewed in English or in Spanish.

\section{Results}

\section{Phase 1: Developing Initial Item Pool}

The first step in building this scale was to develop a list of possible items. A secondary analysis of focus group data obtained from participants of the initial Centering Pregnancy groups identified themes, key words and phrases that described the experience of empowerment in groups [12]. The transcripts were reviewed independently by all three authors for emerging themes and the themes were analyzed until consensus was reached.

Based on our review of the health empowerment literature, we compared these focus group themes to the items of the Empowerment Questionnaire (EQ) developed for the case management of mothers [22, 23]. With permission from the authors, we selected items from the EQ that reflected aspects of the focus group themes.

The final step identified conceptual gaps for which there were no existing items. To ensure that our scale incorporated all aspects of group as well as individual care that might relate to empowerment, we examined the conceptual framework for CenteringPregnancy and the first author's clinical expertise with the CenteringPregnancy model [13]. 
This process aided the development of additional items (e.g., "My healthcare provider respects my decision even if it is different from his/her own."). At the end of this process, we had a total of 54 items representing four dimensions of pregnancy-related empowerment:

- Provider connectedness: A healthcare relationship that minimizes the power differential between clients and providers. These relationships are created within an environment of respect and trust.

- Skillful decision-making: Process by which women come to evaluate and choose a direction that will impact their health.

- Peer Connectedness: A bond between women that develops from the evolution of caring and supportive relationships.

- Gaining voice: The ability of women to be knowledgeable about their health and advocate for their health care options for self and family.

\section{Item reduction, validity and comprehension}

To establish content validity and reduce the items, we asked a panel of seven professional experts across the U.S. to evaluate the items. The 54 items were presented to the experts in random order. Experts evaluated each item for relevance, clarity, conciseness, comprehensiveness of content, and appropriateness for study population. Only items endorsed by at least five out of the seven experts were retained for a content validity index of 0.71 . Revisions were made to improve clarity and conciseness of items and reduce redundancy. For example, one question was eliminated "I can talk about personal problems with other people in my life." As reviewers questioned it's relevancy to prenatal care. A number of questions focused on preferences such as "I prefer to make my own health care decisions during pregnancy...during labor and birth" were condensed due to redundancy and changed to focus on the action rather than preferences. The revised question "Since I began prenatal care, I have been making more decisions about my health" focuses on participant action. This revised scale had 18 items.

Next, we conducted a focus group and cognitive interviews with seven women who completed CenteringPregnancy prenatal care within the past six months. They completed the revised measure prior to the focus group session and were asked about whether the items represented their experiences with CenteringPregnancy. They all agreed that the questions represented their experience in a Centering group and no additional questions were recommended. Women also found that the directions and questions were clear, the form was easy to fill out, and the length of the survey was acceptable (less than 15 minutes to complete). We then conducted individual cognitive "Think Aloud" interviews with six of the focus group participants to obtain additional information to enhance the comprehensibility of the measure among the target population. After each interview the key problems were summarized and revisions were made, followed by additional interviews using the revised questions. The sequence of interviews and scale revisions was iterative. Redundancy was achieved when all major sources of response error were identified and addressed.

\section{Preliminary Psychometric Testing and Revisions}

The next step in the development of the English PRES was to examine the psychometric properties of the 18-item scale. The self-administered scale was given to 135 English-speaking women from three clinics. The survey required less than 10 minutes for the majority of women to complete. All women invited to participate completed a survey for a $100 \%$ response rate. We examined the inter-item correlations and internal consistency reliability. Two items were deleted to increase the alpha reliability coefficient. This resulted in a 16-item scale. All item-to-total scale correlations were positive and ranged from 0.42 to 0.72 . Internal consistency was supported by a Cronbach alpha coefficient of 0.88 . The final mean score was 3.48 (SD 0.55) on a 4-point Likert scale with $1=$ strongly disagree and $4=$ strongly agree. The scale had a sixth grade reading level using the Flesch-Kincaid method [25].

\section{Phase 2: Translating the English version to Spanish}

To translate the PRES from English into Spanish we used the committee method of translation to achieve conceptual equivalence rather than literal translation $[26,27]$. We used three bilingual translators, with Spanish as their primary language, to conduct independent translations. They met to identify any differences and to reach consensus on an integrated version that best captured the intended concepts. Translators also took notes while transcribing to describe their decision-making processes in choosing among alternatives for potential confusing words or terms. The translators also had different ethnic backgrounds to address any potential differences in personal language use and meaning.

When there was no clear consensus on terms or phrases, the alternative translations were addressed by conducting cognitive "think-aloud" interviews with Latina pregnant women like the target population. These interviews were conducted to obtain feedback from women about the translations [26]. Although translation of some words is fairly straightforward, idiomatic expressions are less so. Bilingual translators may interpret meaning of words differently than monolingual (or Spanish as a primary language) participants related to the likelihood of different educational background and socioeconomic status [27]. To avoid any potential bias from the committee of translators, these interviews were conducted by a fourth bilingual interviewer also having Spanish as her primary language. The sequence of interviews and scale revision was iterative. After 11 interviews were completed, redundancy was achieved.

A key finding from our translation strategies included that a direct translation of English into Spanish words would 
have resulted in differences in meaning of words and phrases between languages. For the item "I expect my health care provider to respect my decisions about my pregnancy", there were two options that we included in our think-aloud interviews: espero (hoping) versus quiero (want). For another item "I can tell when I have made a good choice", the options were se (know) versus cuenta (awareness). Feedback also included the need to revise the instructions by adding a descriptor for the type of provider; therefore, "prenatal" was inserted to clarify the type of provider. Interestingly, while women understood the item, "I share my feelings and experiences with other women" consistent with the investigator's intention, several women indicated that although this was beneficial for women, they would share experiences with only immediate family. Overall, women easily comprehended the majority of items and there were few revisions. We also found that the preferred response set for women to indicate their amount of agreement or disagreement was Totalmente en desacuerdo rather than completamente en desacuerdo.

\section{Phase 3: Psychometric Analysis of the PRES in English and Spanish}

We examined the psychometric properties of the scale using a sample of 365 women from an ongoing study of prenatal care in Illinois. As shown in Table 1, 181 of the participants chose to complete the interview in English and
164 in Spanish. This sample is sufficiently large to meet the criterion of at least 10 cases per item for factor analysis separately by language [24]. Of the women interviewed in English, 36.1 \% were Black non-Hispanic, 42.6\% were White non-Hispanic and $21.3 \%$ were Hispanic. Among all Hispanics, the majority identified as Mexican-American. Compared to women who completed the interview in English, women interviewed in Spanish were older, had other children and were more likely to have less than 12 years of education. They also had lower household income, were more likely to be unemployed and were not enrolled in WIC. While the large majority of the sample was enrolled in Medicaid, those completing the English version were more likely to have private insurance (see Table 1).

Item means and standard deviations for each language and the combined sample are shown in Table 2. The mean score was somewhat higher for the women who completed the interview in English than those who completed it in Spanish, but the standard deviations were quite similar. We first examined the item-to-scale correlations and internal consistency reliability. All item-to-total scale correlations were positive and ranged from $0.43-0.77$ for the combined sample, from $0.46-0.70$ for the English version, and from 0.37-0.78 for the Spanish version. Reliability estimates calculated based on Cronbach's alpha also supported high internal consistency for the combined sample $(\alpha=0.94)$, and for the English $(\alpha=0.91)$ and Spanish $(\alpha=0.93)$ versions.

Table 1. Demographic Characteristics of Sample in Phase 3: Psychometric Analysis

\begin{tabular}{|c|c|c|c|c|}
\hline & $\begin{array}{c}\text { English Language } \\
(\mathrm{n}=181)\end{array}$ & $\begin{array}{c}\text { Spanish Language } \\
(\mathrm{n}=164)\end{array}$ & $\begin{array}{c}\text { Total } \\
(\mathrm{N}=365)\end{array}$ & $\mathrm{p}$-value \\
\hline Mean Age (SD) & $24.8(5.79)$ & $29.2(6.22)$ & $27.1(6.40)$ & $\mathrm{p}<0.001$ \\
\hline Age $<20$ years old & $20.7 \%$ & $4.4 \%$ & $12.2 \%$ & $\mathrm{p}<0.001$ \\
\hline Nulliparous & $42.9 \%$ & $24.7 \%$ & $33.3 \%$ & $\mathrm{p}<0.001$ \\
\hline Race & $21.3 \%$ & $100 \%$ & $63.5 \%$ & \\
\hline Hispanic & $42.6 \%$ & $0 \%$ & $19.8 \%$ & $\mathrm{p}<0.001$ \\
\hline Bhite non-Hispanic & $36.1 \%$ & $0 \%$ & $16.7 \%$ & $\mathrm{p}<0.001$ \\
\hline Less than 12 years education & $25.0 \%$ & $47.8 \%$ & $36.7 \%$ & $\mathrm{p}<0.001$ \\
\hline Employed (full or part-time) & $50.6 \%$ & $32.0 \%$ & $41.1 \%$ & $\mathrm{NS}$ \\
\hline Enrolled in Medicaid & $83.5 \%$ & $86.3 \%$ & $85.0 \%$ & $\mathrm{p}<0.001$ \\
\hline Had Private Insurance & $15.9 \%$ & $4.4 \%$ & $9.8 \%$ & $\mathrm{p}<0.05$ \\
\hline Enrolled in WIC & $48.2 \%$ & $36.7 \%$ & $41.1 \%$ & $\mathrm{NS}$ \\
\hline Had spouse, partner, or boyfriend & $89.0 \%$ & $92.8 \%$ & $91.0 \%$ & $\mathrm{NS}$ \\
\hline Received Food Stamps & $49.0 \%$ & $51.0 \%$ & $50.0 \%$ & $\mathrm{p}=0.001$ \\
\hline Household Income & $41.9 \%$ & $52.6 \%$ & $47.5 \%$ & $23.3 \%$ \\
\hline$<12,000$ & $18.7 \%$ & $27.5 \%$ & $29.2 \%$ & \\
\hline \$12,000 - \$17,999 & $39.4 \%$ & $19.9 \%$ & & \\
\hline
\end{tabular}


Table 2. Reliability Analysis, Pregnancy Related Empowerment Scale by Language and Total Scale

\begin{tabular}{|c|c|c|c|c|c|c|}
\hline \multirow[b]{2}{*}{ Item } & \multicolumn{2}{|c|}{$\begin{array}{c}\text { English Language } \\
(\mathrm{n}=181)\end{array}$} & \multicolumn{2}{|c|}{$\begin{array}{c}\text { Spanish Language } \\
(\mathrm{n}=164)\end{array}$} & \multicolumn{2}{|c|}{ Total Sample $(\mathrm{N}=365)$} \\
\hline & Mean & SD & Mean & SD & Mean & SD \\
\hline \multicolumn{7}{|l|}{ Provider Connectedness } \\
\hline $\begin{array}{l}\text { I can ask my health care provider about my } \\
\text { pregnancy. }\end{array}$ & 3.79 & 0.43 & 3.28 & 0.47 & 3.53 & 0.51 \\
\hline $\begin{array}{l}\text { I have enough time with my health care provider to } \\
\text { discuss my pregnancy. }\end{array}$ & 3.74 & 0.46 & 3.08 & 0.59 & 3.40 & 0.62 \\
\hline My health care provider listens to me. & 3.77 & 0.46 & 3.29 & 0.53 & 3.52 & 0.55 \\
\hline My health care provider respects me. & 3.77 & 0.42 & 3.32 & 0.51 & 3.54 & 0.52 \\
\hline $\begin{array}{l}\text { I expect my health care provider to respect my } \\
\text { decisions about my pregnancy. }\end{array}$ & 3.73 & 0.44 & 3.31 & 0.49 & 3.51 & 0.51 \\
\hline $\begin{array}{l}\text { My health care provider respects my decision, even } \\
\text { if it is different than her/his recommendation. }\end{array}$ & 3.44 & 0.65 & 3.16 & 0.56 & 3.30 & 0.62 \\
\hline \multicolumn{7}{|l|}{ Skillful Decision-Making } \\
\hline $\begin{array}{l}\text { I take responsibility for the decisions I make about } \\
\text { my pregnancy like eating healthy food. }\end{array}$ & 3.73 & 0.44 & 3.21 & 0.57 & 3.46 & 0.57 \\
\hline I can tell when I have made a good health choice. & 3.52 & 0.53 & 3.14 & 0.57 & 3.33 & 0.58 \\
\hline $\begin{array}{l}\text { Since I began prenatal care, I have been making } \\
\text { more decisions about my health. }\end{array}$ & 3.56 & 0.55 & 3.16 & 0.61 & 3.35 & 0.61 \\
\hline \multicolumn{7}{|l|}{ Peer Connectedness } \\
\hline $\begin{array}{l}\text { Women need to share experiences with other } \\
\text { women when they are pregnant. }\end{array}$ & 3.38 & 0.58 & 3.20 & 0.50 & 3.28 & 0.55 \\
\hline $\begin{array}{l}\text { I share my feelings and experiences with other } \\
\text { women. }\end{array}$ & 3.18 & 0.69 & 3.00 & 0.58 & 3.09 & 0.64 \\
\hline \multicolumn{7}{|l|}{ Gaining Voice } \\
\hline $\begin{array}{l}\text { I know if I am gaining the right amount of weight } \\
\text { during my pregnancy. }\end{array}$ & 3.08 & 0.69 & 2.95 & 0.58 & 3.01 & 0.64 \\
\hline $\begin{array}{l}\text { I have a right to ask questions when I don't } \\
\text { understand something about my pregnancy. }\end{array}$ & 3.69 & 0.49 & 3.36 & 0.51 & 3.52 & 0.53 \\
\hline $\begin{array}{l}\text { I am able to change things in my life that are not } \\
\text { healthy for me. }\end{array}$ & 3.62 & 0.50 & 3.29 & 0.50 & 3.45 & 0.52 \\
\hline I am doing what I can to have a healthy baby. & 3.73 & 0.46 & 3.44 & 0.50 & 3.58 & 0.50 \\
\hline $\begin{array}{l}\text { If something is going wrong in my pregnancy, I } \\
\text { know who to talk to. }\end{array}$ & 3.73 & 0.45 & 3.33 & 0.49 & 3.52 & 0.51 \\
\hline Total scale score & 3.59 & 0.52 & 3.22 & 0.53 & 3.40 & 0.56 \\
\hline Cronbach alpha & .91 & - & .93 & - & 0.94 & - \\
\hline
\end{tabular}

We also used confirmatory factor analysis to determine a comparative fit index (CFI), root mean square error of approximation (RMSEA), Standardized Root Mean Square Residual (SRMR) and Chi-Square statistic for the combined (English and Spanish) sample and for each language separately [28]. For the total sample, the CFI was 0.922 , exceeding the recommended criteria of .90 [29]. The RMSEA was 0.08 , meeting the recommended criteria of 0.08 [30]. The SRMR was .057 and the Chi-Square statistic was $347.489(\mathrm{DF}=101)$ with a $\mathrm{p}$-value $<.001$. A SRMR less than .1 is recommended. The Chi-Square statistic was significant indicating a less than adequate model fit. However, the Chi-Square is sensitive to sample size. With a large sample size, the Chi-square values will be inflated (statistically significant), thus might erroneously imply a poor data-to-model fit [31]. For the Spanish sample, the CFI was 0.951 , the RMSEA was 0.06 , the SRMR was .064 and the Chi-Square statistic was 147.211 ( $\mathrm{DF}=97)$ with a p-value of .001. For English group, and the CFI was .942, the RMSEA was 0.074, the SRMR was .058, and the Chi-Square statistic was $179.328(\mathrm{DF}=97)$ with a $\mathrm{p}$-value $<.001$. These results indicated that the confirmatory factor analysis model adequately fit the sample data for the overall scale and for the English and Spanish versions. Table 3 presents the factor loadings.

Confirmatory factor analysis was performed to examine construct validity, specifically, whether there was a match between the data and the conceptual model hypothesized as having four subscales. A comparative fit index (CFI) and root mean square error of approximation (RMSEA) were determined for the combined (English and Spanish) sample and for each language separately [28]. For the total sample, the CFI was 0.922 , exceeding the recommended criteria of .90 [29]. The RMSEA was 0.08, meeting the recommended criteria of 0.08 [30]. The factor loadings are presented in Table 3. For the Spanish sample, the CFI was 0.951 and the RMSEA was 0.06. For English group, and the CFI was .942 and the RMSEA was 0.074 . These results indicated that the CFA model adequately fit the sample data for the overall scale and for the English and Spanish versions. 
Table 3. Confirmatory Factor Analyses for the Pregnancy Related Empowerment Scale by Language and Total Scale

\begin{tabular}{|c|c|c|c|}
\hline & \multicolumn{3}{|c|}{ Factor Loadings } \\
\hline Item & $\begin{array}{l}\text { English Language } \\
\qquad(\mathrm{n}=181)\end{array}$ & $\begin{array}{c}\text { Spanish } \\
\text { Language } \\
(\mathrm{n}=164)\end{array}$ & $\begin{array}{l}\text { Total Sample } \\
(\mathrm{N}=365)\end{array}$ \\
\hline \multicolumn{4}{|l|}{ Provider Connectedness } \\
\hline I can ask my health care provider about my pregnancy. & 0.72 & 0.64 & 0.75 \\
\hline $\begin{array}{c}\text { I have enough time with my health care provider to discuss my } \\
\text { pregnancy. }\end{array}$ & 0.70 & 0.77 & 0.79 \\
\hline My health care provider listens to me. & 0.76 & 0.83 & 0.81 \\
\hline My health care provider respects me. & 0.78 & 0.79 & 0.82 \\
\hline $\begin{array}{l}\text { I expect my health care provider to respect my decisions about my } \\
\text { pregnancy. }\end{array}$ & 0.83 & 0.61 & 0.80 \\
\hline $\begin{array}{l}\text { My health care provider respects my decision, even if it is different } \\
\text { than her/his recommendation. }\end{array}$ & 0.66 & 0.47 & 0.60 \\
\hline \multicolumn{4}{|l|}{ Skillful Decision-Making } \\
\hline $\begin{array}{l}\text { I take responsibility for the decisions I make about my pregnancy } \\
\text { like eating healthy food. }\end{array}$ & 0.62 & 0.73 & 0.74 \\
\hline I can tell when I have made a good health choice. & 0.76 & 0.74 & 0.77 \\
\hline $\begin{array}{l}\text { Since I began prenatal care, I have been making more decisions } \\
\text { about my health. }\end{array}$ & 0.71 & 0.60 & 0.69 \\
\hline \multicolumn{4}{|l|}{ Peer Connectedness } \\
\hline $\begin{array}{l}\text { Women need to share experiences with other women when they are } \\
\text { pregnant. }\end{array}$ & 0.82 & 0.77 & 0.53 \\
\hline I share my feelings and experiences with other women. & 0.45 & 0.79 & 0.44 \\
\hline \multicolumn{4}{|l|}{ Gaining Voice } \\
\hline $\begin{array}{c}\text { I know if I am gaining the right amount of weight during my } \\
\text { pregnancy. }\end{array}$ & 0.42 & 0.46 & 0.42 \\
\hline $\begin{array}{l}\text { I have a right to ask questions when I don't understand something } \\
\text { about my pregnancy. }\end{array}$ & 0.86 & 0.62 & 0.78 \\
\hline I am able to change things in my life that are not healthy for me. & 0.81 & 0.78 & 0.82 \\
\hline I am doing what I can to have a healthy baby. & 0.83 & 0.66 & 0.78 \\
\hline If something is going wrong in my pregnancy, I know who to talk to. & 0.83 & 0.77 & 0.83 \\
\hline
\end{tabular}

\section{Discussion}

The Pregnancy-Related Empowerment Scale (PRES) is a valid and reliable measure of women's health-related empowerment during pregnancy. Based on our review of the literature and an analysis of the conceptual framework for CenteringPregnancy, we identified four dimensions of pregnancy-related empowerment that should be captured by the PRES: provider connectedness, skillful decision-making, peer connectedness and gaining voice. Confirmatory factor analysis in this study supported these four subscales. Content validity was confirmed by an expert panel. The final scale includes items assessing each of these dimensions, as supported by confirmatory factor analysis. Translation into Spanish used consensus translation to ensure conceptual equivalence, followed by cognitive interviews with low-income women to ensure that the scale was understandable. Reliability, as determined by internal consistency, was very high overall and for both the English and Spanish versions. The scale is brief, only 16 items, which facilitates ease of administration and minimizes respondent burden, and its sixth grade reading level makes the scale appropriate for use with women with low literacy.

Our findings indicate that use of a professional expert panel to develop items and translation by committee were not sufficient for scale development. Interviews with women in both English and Spanish were essential for developing items that were fully understood by the women. The cognitive interview provides a way to obtain this key information and usually achieves saturation with relatively few interviews. This procedure enhances both validity and ease of administration, because any lack of clarity in the scale instructions and items has been resolved.

A limitation of this scale is a lack of evaluation of the 5 items that are specific to group prenatal care. These specific items highlight unique differences between group and individual care and thus could not be included for women receiving individual prenatal care. Knowing if these questions are reliable and valid for evaluating group process in prenatal care will be important in the evaluation of the efficacy of the group versus individual prenatal care. Secondly, as this scale was developed from Latina and 
African American low-income populations it's efficacy with other populations may be limited. Further research with other population and cultural groups may be necessary to improve reliability across broader prenatal populations.

\section{Conclusions}

A strong evidence base is needed to generate a sustained effort to change practice and deliver care in a manner that is patient-centered and empowering. The PRES is a reliable and valid measure of pregnancy-related empowerment that allows researchers and providers to document whether an innovation increases women's pregnancy-related empowerment and whether empowerment is a pathway through which perinatal outcomes are improved.

\section{Acknowledgements}

This research was supported by the University of Illinois at Chicago, College of Nursing, the Internal Research Support Program, the University of Illinois at Chicago, Campus Research Board Pilot Grant Program, and the Health Resources and Services Administration, Maternal Child Health Bureau, Grant R40MC17174. We wish to thank Sharon Rising, MSN, CNM, FACNM for sharing her data and her advice during the development of this scale. We also want to thank the members of the Expert Panel and the women who participated in this study.

\section{REFERENCES}

[1] Portela, A., \& Santarelli, C. Empowerment of Women, Men, Families and Communities: True Partners for Improving Maternal and Newborn Health. British Medical Bulletin, 67, 59-72, 2003.

[2] Public Health Service Expert Panel on the Content of Prenatal Care. Caring for Our Future, the Content of Prenatal Care: A report of the Public Health Service Expert Panel on the Content of Prenatal Care. Washington, D.C., 1989.

[3] United States Department of Health and Human Services. Healthy People Maternal, Infant and Child Health: Objectives, online available from http://www.healthypeople.gov/2020/topicsobjectives2020/ob jectiveslist.aspx?topicId $=26$.

[4] Phelan, S. Pregnancy: A "Teachable Moment" for Weight Control and Obesity Prevention, American Journal of Obstetrics and Gynecology, 202 (2): 135 e131-138, 2010.

[5] Sui, Z., Turnbull, D. \& Dodd, J. Enablers and Barriers to Making Healthy Change during Pregnancy in Overweight and Obese Women, Australia Medical Journal, 6(11): 565-77, 2013.

[6] Save the Children. The State of the World's Mothers, 2015.

[7] Institute of Medicine. Crossing the Quality Chasm: A New
Health System for the 21st Century. Washington, D.C.: National Academies Press, 2001.

[8] Holmstrom, I., \& Roing, M. The Relation between Patient-Centeredness and Patient Empowerment: a Discussion on Concepts. Patient Education Counseling, 79(2), 167-172, 2010. doi: 10.1016/j.pec.2009.08.008

[9] Rohrer, J. E., Wilshusen, L., Adamson, S. C., \& Merry, S. Patient-Centeredness, Self-Rated Health, and Patient Empowerment: Should Providers Spend More Time Communicating with their Patients? Journal of Evaluation in Clinical Practice, 14(4), 548-551, 2008. doi: 10.1111/j.1365-2753.2007.00914.x

[10] Ickovics, J.R., Kershaw, T.S., Westdahl, C., Magriples, U., Massey, Z., Reynolds, H., \& Rising, S. Group Prenatal Care and Perinatal Outcomes A Randomized Controlled Trial. Obstetrics \& Gynecology, 110 (2, Part 1):330-339, 2007.

[11] Picklesimer, A. H., Billings, D., Hale, N., Blackhurst, D., \& Covington-Kolb, S. The effect of CenteringPregnancy Group Prenatal Care on Preterm Birth in a Low-Income Population. American Journal of Obstetrics and Gynecology, 206: 415 e1-7, 2012.

[12] Rising, S. S. Centering pregnancy. An Interdisciplinary Model of Empowerment. Journal of Nurse Midwifery, 43(1), 46-54, 1998.

[13] Rising, S. S., Kennedy, H. P., \& Klima, C. S. Redesigning prenatal care through CenteringPregnancy. Journal of .Midwifery and Women's Health, 49(5), 398-404, 2004.

[14] Evans, W. D., Abroms, L. C., Poropatich, R., Nielsen, P. E., \& Wallace, J. L. Mobile Health Evaluation Methods: The Text4Baby Case Study. Journal of Health Communication, 17(sup1), 22-29, 2012.

[15] Lu, M. C., Kotelchuck, M., Hogan, V. K., Johnson, K., \& Reyes, C. Innovative Strategies to Reduce Disparities in the Quality of Prenatal Care in Under-resourced Settings. Medical Care Research and Review, 67(5 suppl), 198S-230S, 2010.

[16] Nutting, P. A., Miller, W. L., Crabtree, B. F., Jaen, C. R., Stewart, E. E., \& Stange, K. C. Initial Lessons from the First National Demonstration Project on Practice Transformation to a Patient-Centered Medical Home. The Annals of Family Medicine, 7(3), 254-260, 2009.

[17] Payne, M. Storey, M., Sanders, D. Pregnancy Partners: A Patient Navigator System to Improve Early Prenatal Care. Washington State Journal of Public Health Practice 4, S1, 32, 2011.

[18] Herbert, R. J., Gagnon, A. J., Rennick, J. E., \& O'Loughlin, J. L. A Systematic Review of Questionnaires Measuring Health-Related Empowerment. Research and Theory Nursing Practice, 23(2), 107-132, 2009.

[19] Shearer, N. B., Fleury, J., Ward, K. A., \& O'Brien, A. M. Empowerment Interventions for older adults. Western Journal of Nursing Research, 34(1), 24-51, 2012. doi: $10.1177 / 0193945910377887$

[20] Bulsara, C., Styles, I., Ward, A. M., \& Bulsara, M. The psychometrics of Developing the Patient Empowerment Scale. Journal of Psychosocial Oncology, 24(2), 1-16, 2006. doi: 10.1300/J077v24n02_0

[21] Rogers, E. S., Chamberlin, J., Ellison, M. L., \& Crean, R. A. 
Consumer-Constructed Scale to Measure Empowerment among Users of Mental Health Services. Psychiatric Services, 48(8), 1042-1047, 1997.

[22] Becker, J., Kovach, A., \& Gronseth, D. Individual Empowerment: How Community Health Workers Operationalize Self-determination, Self-sufficiency and Decision-making Capabilities of Low-income Mothers. Journal of Community Psychology, 32(3), 327-342, 2004.

[23] Kovach, A., Becker, J., \& Worley, H. The Impact of Community Health Workers on the Self-determination, Self-sufficiency and Decision making-ability of Low-income Women and Mothers of Young Children. Journal of Community Psychology, 32 (3), 343-356, 2004.

[24] DeVillis, R.F. Scale Development: Theory and Applications. Newbury Park: Sage Publications, 1991.

[25] Flesch, R. A New Readability Yardstick. J Applied Psychology, 32(3), 221-233, 1948.

[26] Harkness, J., \& Schoua-Glusberg, A. Questionnaires in Translation. ZUMA-Nachrichten Spezial (ZUMA News Special), 3, 1998.
[27] Warnecke, R. B., Ferrans, C. E., Johnson, T. P., Chapa-Resendez, G., O'Rourke, D. P., Chavez, N., ... Lad, T. Measuring Quality of Life in Culturally Diverse Populations. Journal of the National Cancer Institute Monographs, 29-38, 1996.

[28] McDonald, R.P. \& Ho, M. Principles and Practice in Reporting Statistical Equation Analyses. Psychological Methods, 7(1), 64-82, 2002.

[29] Hu, L.T. \& Bentler, P.M. Cutoff Criteria for Fit Indexes in Covariance Structure Analysis: Conventional Criteria versus New Alternatives. Structural Equation Modeling, 6 (1), 1-55, 1999.

[30] MacCallum, R.C., Browne, M.W., \& Sugawara, H., M. Power analysis and Determination of Sample Size for Covariance Structure Modeling. Psychological Methods, 1 (2), 130-49, 1996.

[31] Iacobucci, D. Structural Equations Modeling: Fit Indices, Sample Size, and Advanced Topics Journal of Consumer Psychology, 20, 90-98, 2010. 